\title{
Foot Reconstruction of Severe Bone and Soft Tissue Landmine Injury
}

Abdulmalik Adel $^{1 *}$, Salem Elmabsout ${ }^{2}$ and Randa Aldaghili ${ }^{2}$

${ }^{1}$ The Libyan International Medical University, Benghazi, Libya

${ }^{2}$ Aljala hospital, Benghazi, Libya

"Corresponding author: Abdulmalik Adel, The Libyan International Medical University, Benghazi, Libya' Tel: +218925953518; E-mail: makryd324@gmail.com

Received Date: Nov 09, 2018; Accepted Date: Nov 26, 2018; Published Date: Dec 05, 2018

Copyright: @ 2018 Adel A, et al. This is an open-access article distributed under the terms of the Creative Commons Attribution License, which permits unrestricted use, distribution, and reproduction in any medium, provided the original author and source are credited.

\begin{abstract}
Landmine Injury to the foot and ankle as high-force energy can be devastating to a different structure including bone, muscles, vessels, and nerves. The degree of tissue destruction and often other surgical evaluation most likely to affects the decision of whether to amputate or attempt a reconstruction. In Literature, previous studies show that immediate amputation in patients with high Mangled Extremity Severity Score (MESS) had a very good prognosis compared with reconstruction. In this paper, we report a case of a 28-male presented to the Emergency Department at ALJALA hospital after 30 minutes of crushing his right foot by direct contact with a landmine. Assessment of the patient revealed poor general state and the foot was severely mangled despite $>7$ on Mangled Extremity Severity Score (MESS). Limb salvage was used with Aggressive debridement, reduction with external fixation, skin graft with big toe amputation and later replace of skin graft with sural flap. After one year of treatment, all wounds healed completely with little pain, satisfactory motor and sensory functions were achieved and the patient returns to his previous job as vehicle driver. In conclusion, the treatment of mangled extremity should be based on clinical evaluation of every patient. Guidelines and scores are helpful, but should not be considered as fundamental criteria in clinical decisions.
\end{abstract}

Keywords: Land mind injury; Reconstruction; Amputation; Mangled extremity; Mangled extremity evaluation

\section{Case Report}

A 28-year-old Libyan male was admitted to the orthopedic department in the ALJALA hospital in Benghazi with the diagnosis of a severe bone and soft tissue injury of the right foot. After Land mind injury, the patient was transported to the emergency department (ED) 30 min after the injury.

On examination the patient was conscious vitally unstable with hypotension (90/60 $\mathrm{mmHg}$ ), Pulse (135 beats/minute), cool limb and multiple penetrating injuries to abdomen, pelvis, chest, both lower limbs and multiple small faces injuries with ash and the smell of smoke and pool of venous bleeding which controlled by tourniquet and start resuscitation before a complete examination of the patient.

The right foot had severe bone and soft tissue injuries with about 25 $\mathrm{cm}$ contaminated wound that extends from posteromedial aspect lower leg to medial, plantar and lateral aspect up to dorsum of foot (Figure 1). Vessels: posterior tibial Artery was injured, and the dorsalis pedis artery was not palpable, but the area over its course was intact, Bones: fractures of navicular, calcaneus and talus with amputation of the distal phalanx of the big toe and exposed bone of the second toe, Tendons: severely smashed and contaminated with a large area of necrosis, Nerves: Because of a large area of burn and smashed soft tissue orthopedic surgeons weren't able to identify the Nerves, however the Patient report loss of feeling in his lower extremity direct after the injury.

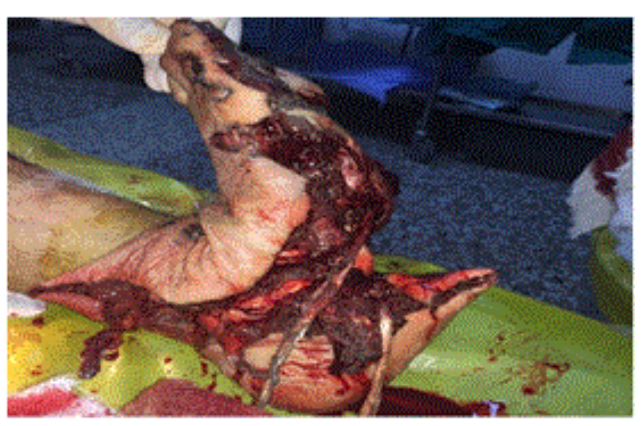

Figure 1: Patient leg at the time of presentation.

\section{X-ray}

According to X-ray films, the patient was diagnosed with open wound fracture in the upper shaft of right fibula, navicular, calcaneus and talus with dislocation of most joints of the foot (inter tarsal, tarsometatarsal and metatarsophalangeal joints) and amputation distal phalanx of the big toe, ankle joint was preserved. X-ray Also revealed numerous foreign bodies in Both Legs (Figure 2). 
Citation: Adel A, Elmabsout S, Aldaghili R (2018) Foot Reconstruction of Severe Bone and Soft Tissue Landmine Injury. Med Rep Case Stud 3:

Page 2 of 4

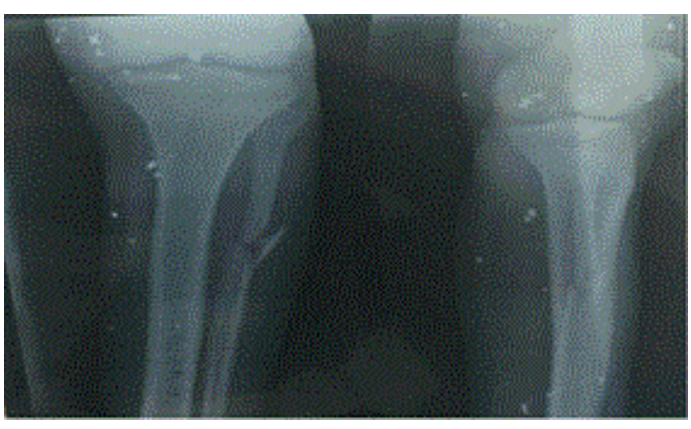

Figure 2: X-ray image of both legs shows fracture at upper shaft of right fibula with numerous foreign bodies in both legs.

\section{Ultrasound}

Abdominal ultrasound confirms large bowel injury and lapratomy was done; no other injuries were found.

\section{MESS}

Mangled Extremity Severity Score (MESS) of the patient is shown in Table 1.

\begin{tabular}{|c|c|}
\hline & Points \\
\hline \multicolumn{2}{|l|}{ A. Skeletal/soft tissue injury } \\
\hline Low energy (stab; simple fracture; "civilian" gunshot wound & 1 \\
\hline Medium energy (open or multiple fractures, dislocation) & 2 \\
\hline High energy (close-range shotgun or "military" gunshot wound, crush injury) & 3 \\
\hline Very high energy (above+gross contamination, soft tissue avulsion) & 4 \\
\hline \multicolumn{2}{|l|}{ B. Limb ischemia } \\
\hline Pulse reduced or absent but perfusion normal & $1^{*}$ \\
\hline Pulseless; parasthesias, diminished capillary refill & $2^{*}$ \\
\hline Cool, paralyzed, insensate, numb & $3^{*}$ \\
\hline \multicolumn{2}{|l|}{ C. Shock } \\
\hline Systolic blood pressure always $>90 \mathrm{~mm} \mathrm{Hg}$ & 0 \\
\hline Hypotensive transiently & 1 \\
\hline Persisted hypotension & 2 \\
\hline \multicolumn{2}{|l|}{ D. Age (y) } \\
\hline$<30$ & 0 \\
\hline $30-50$ & 1 \\
\hline$>50$ & 2 \\
\hline
\end{tabular}

Table 1: Mangled Extremity Severity Score (MESS).

\section{Management Strategy}

\section{Preliminary management}

A preliminary proceeding conducted in the emergency department included air way patent, resuscitation by giving stat iv fluid $1000 \mathrm{cc}$ gelofusine and $1000 \mathrm{cc}$ normal saline with potent analgesia and extensive washing of the wounds with a saline solution and betadine. Then the bleeding was controlled by applying pressure dressing and proximal tourniquet. After one hour of assessment and preparation, the patient was transferred to the orthopedic operation room.

\section{Management in the operation room}

Resuscitation was continued and the patient was intubated. Arterial flow was doubtful by checking capillary refilling of toes. Then pneumatic tourniquet was applied, draping, irrigation of foot and removed foreign bodies with exposed of the wound to reassessment which showed severe injuries in all medial, planter and lateral aspect of 
foot. Posterior tibial vessels was burned, dorsalis pedes were not palpable but were over the course looks intact, with fractures in the navicular, calcaneus and talus. Dislocation of most joints of the foot (inter tarsal, tarsometatarsal and metatarso phalangeal joints), amputation distal phalanx of the big toe, ankle joint was preserved, and flexor tendon was smashed and burned with loss of skin cover of medial and planter aspect of mid foot and big toe, (gastello type iii c). Doctor discussed with the patient and his family about advantages and disadvantages of limb salvage and amputation in his situation and they accept the doctor's idea about reconstruction and amputation can be done any time later. After getting writing consent, surgeons start aggressive debridement of soft tissues, multiple k- wires were fixed at medial and lateral border of foot, and trans articular Hoffman ii external fixator applied (two pins in distal tibia-trans calcaneal middle thread pin-pin to the second metatarsal) (Figure 3). Skin was approximated and there were still raw area on medial, planter aspect of mid foot and big toe and the tip of the second toe. Before transferring to intensive care unit, patient extubated, received four units of blood and applied antiseptic dressing on wound.

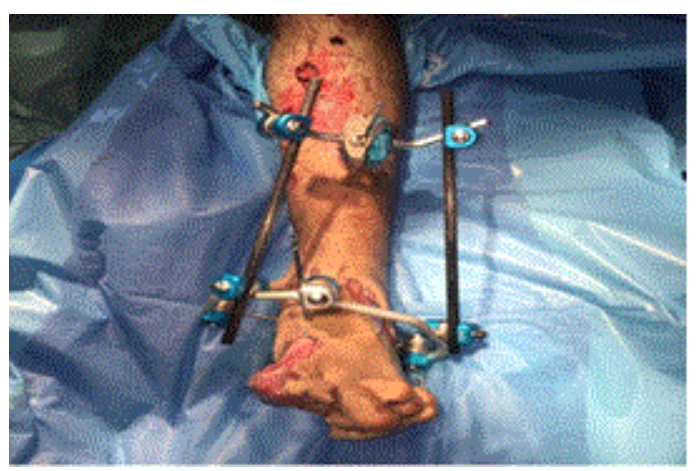

Figure 3: Multiple k-wires fixed medial and lateral border of right foot.

\section{Post-operative management}

The patient was placed on monitoring, dressing daily with an assessment of circulation and wound status periodically. Triple IV antibiotic regime (ceftriaxone $1 \mathrm{~g} / 12$ hours, Gentamycine $80 \mathrm{mg} / 8$ hours, Metronidazole $500 \mathrm{mg} / 8$ hours) was given. Also, potent analgesia was given tells the wounds were ready for grafting.

After six weeks, external fixator removed and skin graft operation was done by plastic surgeons. During months patient starts complaining of pressure pain at the site of skin graft and also ulcers at pressure area with exposed bone of big toe (Figure 4).

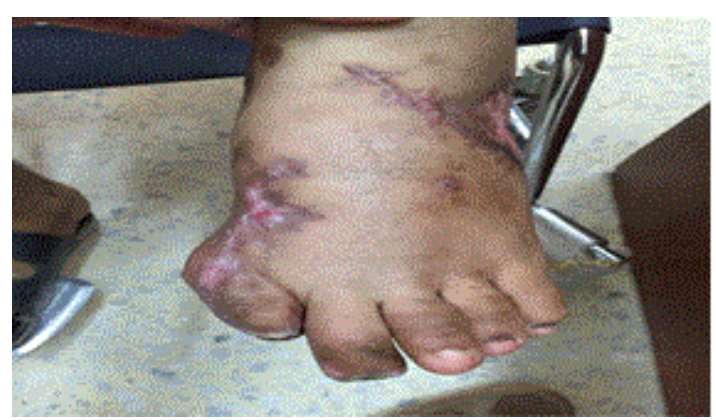

Figure 4: Ulceration after 3 months of skin graft with exposed bone of big toe.

The third operation was done which disarticulation of big toe at the level of metatarso phalangeal joint. After wound healing, we advised for full thickness flap which done after months by rotational sural flap (Figure 5) and the patient was still following us, up to this moment.

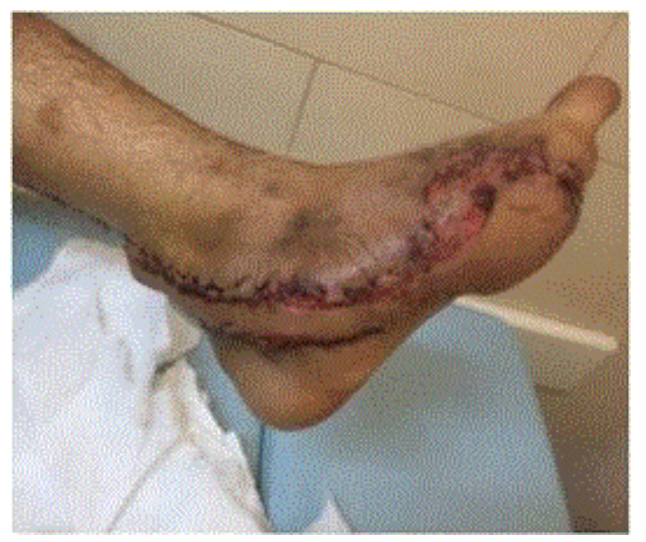

Figure 5: After wound healing shows full thickness flap done by rotational sural flap.

\section{Results}

After two years, the patient appears for follow-up. All wound were healed with little pain (Figure 6), and there was no pathological mobility of bone fragments. X-ray images taken in two projections revealed post-traumatic osteoarthritic changes in tarsal bones (Figure 7). The patient was very satisfied with the treatment result with satisfactory motor and Sensory functions, and he returns to his previous job as a vehicle driver. 


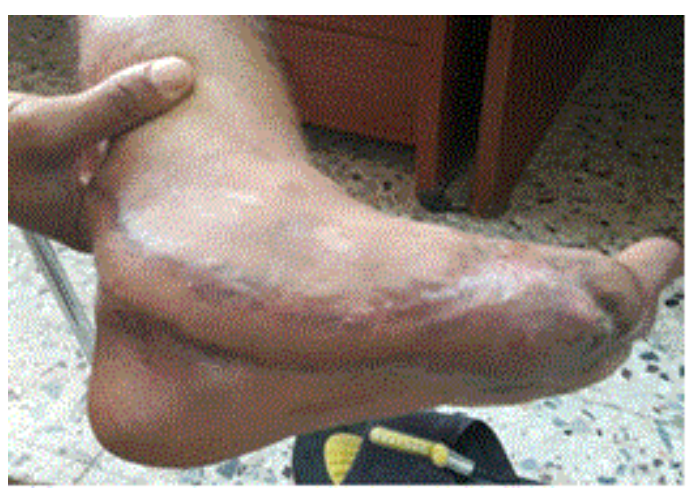

Figure 6: Patient's right foot after two year treatment, all wounds healed without infection or soft tissue necrosis.

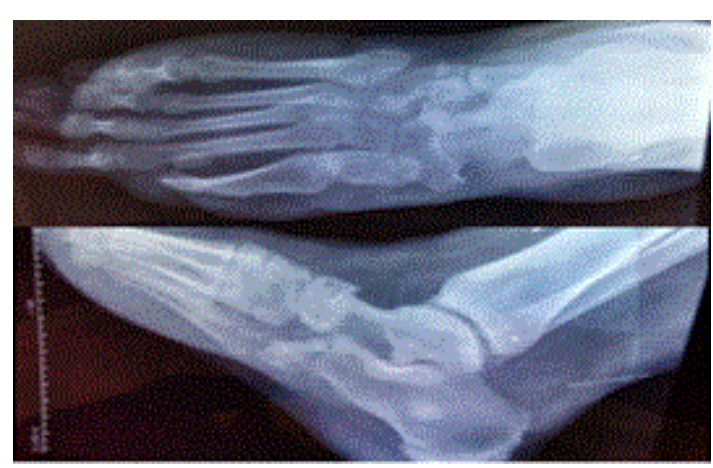

Figure 7: Lateral and anterior x-ray projection of patient's right foot after one year follow-up, the films show osteoarthritic in tarsal bones with no other pathological abnormalities.

\section{Discussion}

Injury to lower extremity by high-force energy, often severely affects the foot and ankle [1]. Secondary to continued surgical advances, many lower extremities can undergo limb salvage procedures but the decision to amputate or perform limb salvage of severely injured mangled extremity remains a difficult dilemma for vascular and orthopedic surgeons [2]. Scoring systems like Mangled Extremity Severity Score (MESS) are frequently used guidelines for discriminating between limbs that are Salvageable and those that are unsalvageable [3], According to these scores early elective amputation treatment is frequently performed in cases that despite 7 or more [4-6]. However, MESS system though an excellent tool to predict limb integrity and evaluate the patients susceptibility to the type of treatment was found, it can't be used in every patient with severe mangled foot. Because of this, we see limb salvage should be attempted whenever possible, and, basic principles must be followed to optimize treatment [7].

\section{Conclusion}

The utility of guidelines in determining the optimize treatment to mangled extremity was proven as an accurate method in the majority of cases. However it can't be considered as fundamental criteria, and clinical evaluation for every patient should be done. Future researches are needed to determine which injury patterns should undergo to early amputation and which can be salvaged with good outcomes.

\section{References}

1. Myerson MS (1994) Morbidity after crush Injuries to the foot. J Orthop Trauma 8: 343-349.

2. Krettek C, Seekamp A, Kontopp H, Tesherne H (2001) Hannover Fracture Scale '98-re-evaluation and new perspective of an established extremity salvage score. Injury 32: 317-328.

3. Johansen K, Daines M, Howey T, Helfet D, Hansen ST Jr. (1990) Objective criteria accurately predict amputation following lower extremity trauma. J Trauma 30: 568-572.

4. Kumar MK, Badole CM, Patond KR (2007) Salvage versus amputation: Utility of mangled extremity severity score in severely injured lower limbs. Indian J Orthop 41: 183-187.

5. Sharma S, Devgan A, Marya KM, Rathee N (2003) Critical evaluation of mangled extremity severity scoring system in Indian patients. Injury 34 : 493-496.

6. Edelstein DA, Florescu I (2016) Crushing injuries of the foot and ankle, with Complex open fractures result of a prospective study with a 3 year follow-up. J Med Life 9: 255-258.

7. Tintle SM, Keeling JJ, Shawen SB (2009) Combat Foot and ankle Trauma. J Surg Orthop Adv 19: 70-76. 